\title{
Article
}

\section{Efficient Removal of Cr (VI) with Biochar and Parameters Opti- mized by Response Surface Methodology}

\author{
Hao Peng *, Jing Guo
}

\begin{abstract}
Chongqing Key Laboratory of Inorganic Special Functional Materials, College of Chemistry and Chemical Engineering, Yangtze Normal University, Fuling, Chongqing 408100, P. R. China; cquguojing@126.com (J. Guo)

* Correspondence: cqupenghao@126.com (H. Peng)
\end{abstract}

\begin{abstract}
A highly efficient reduction process of $\mathrm{Cr}(\mathrm{VI})$ with biochar was conducted in this paper. The results showed that nearly $100 \% \mathrm{Cr}$ (VI) was reduced at selected reaction conditions: the dosage of biochar at $\mathrm{m}(\mathrm{C}) / \mathrm{m}(\mathrm{Cr})=3.0$, reaction temperature of $90{ }^{\circ} \mathrm{C}$, reaction time at $60 \mathrm{~min}$ and concentration of $\mathrm{H} 2 \mathrm{SO} 4$ of $20 \mathrm{~g} / \mathrm{L}$, respectively. The reduction kinetics analysis demonstrated that the reduction of $\mathrm{Cr}$ (VI) fitted well with the pseudo-first-order model and the apparent activation energy was calculated to $40.24 \mathrm{~kJ} / \mathrm{mol}$. Response surface methodology confirmed that all the experimental parameters had positive effect on the reduction of $\mathrm{Cr}(\mathrm{VI})$. The influence of each parameter on the reduction process followed the order: dosage of biochar> Concentration of H2SO4 > Reaction Temperature $>$ Reaction Time. This paper provided a versatile strategy for treatment of wastewater containing $\mathrm{Cr}(\mathrm{VI})$ and showed a bright tomorrow for wastewater treatment.
\end{abstract}

Keywords: Chromium; Response surface methodology; Reduction; Biochar

\section{Introduction}

Chromium pollution is a serious environmental problem and $\mathrm{Cr}$ (VI) has been classified in Group 1 by IARC (International Agency for Research on Cancer) [1-5]. Cr (VI) has many negative impacts on earthworms, plants, fish and so on. It will increase the reproduction and mortality of earthworms, and is toxic on kidney and cells for animals and humans, etc. In recent years, many technologies had been applied to treat the wastewater containing $\mathrm{Cr}$ (VI) [6]. The physicochemical technology (like ion exchange, membrane filtrate, chemical precipitation, etc.) were easy to conduct with high removing efficiency [7-10]. The so-called electrochemical technology associated with electricity showed high removal efficiency and being proud of clean and environmental-friendly [11-13]. Photocatalysis and nanotechnology were also developed for treatment of wastewater and showed great performance [14, 15]. While the problems like large scale application, secondary pollution, high cost were remained. Therefore, it is urgent to develop useful technologies for $\mathrm{Cr}$ (VI) treatment [16-18]. Recently, reduction of $\mathrm{Cr}$ (VI) to $\mathrm{Cr}$ (III) had attracted much more attention $[12,13,19-21]$.

Biochar derived from plant and animal wastes was a typical adsorbent to remove inorganic and organic pollutants in water due to its low-cost and abundant feed stock availability [22-24]. In addition, the large surface area, high mineral content, and rich oxygencontaining functional groups of biochar were favorable for adsorption of wastewater contaminants such as antibiotics, dyes, and heavy metals [25-27]. Thus, biochar was applied to adsorb chromium (VI) in this paper (actually biochar was acted as a reductant and the adsorption process was proved to be a reduction process). The experimental parameters including the dosage of biochar, reaction temperature, reaction time and concentration of $\mathrm{H} 2 \mathrm{SO} 4$ on the reduction process were investigated. Also, the reduction kinetics analysis was done. 


\section{Materials and Methods}

\subsection{Materials}

K2Cr2O7, H2SO4 and biochar were of analytical grade and used as received without further purification, which were purchased from Kelong Co., Ltd, Chengdu, China. All solutions were prepared with deionized water with a resistivity greater than $18 \mathrm{M} \Omega / \mathrm{cm}$ (HMC-WS10) [12, 13, 19, 28].

\subsection{Experimental procedure}

All the experiments were conducted in a beaker placed in a thermostatic water bath with a temperature precision of $\pm 0.1{ }^{\circ} \mathrm{C}[12,13]$. In the batch experiments, $100 \mathrm{~mL} 1000 \mathrm{mg} / \mathrm{L}$ $\mathrm{Cr}$ (VI) solution was prepared by dissolving amount of $\mathrm{K} 2 \mathrm{Cr} 2 \mathrm{O} 7$ in the deionized water, then the prepared biochar was added into the beaker as the solution was heated to a predetermined temperature. After a required reaction time, the solution with $\mathrm{Cr}$ (III) and retained biochar were separated by vacuum filtration. The concentration of $\mathrm{Cr}$ (VI) in the filtrate was determined by ICP-OES $[12,13,21]$, and the reduction efficiency ( $\eta$ ) of $\mathrm{Cr}$ (VI) was calculated following Equation (1):

$$
\eta=\frac{C_{0}-C_{t}}{C_{0}} \times 100 \%
$$

Where, $\mathrm{C} 0$, is the initial concentration of $\mathrm{Cr}(\mathrm{VI})$ in the solution, $\mathrm{mg} / \mathrm{L}$; $\mathrm{Ct}$, is the concentration of $\mathrm{Cr}(\mathrm{VI})$ in the solution at reaction time of $\mathrm{t}, \mathrm{mg} / \mathrm{L}$.

\subsection{Response surface optimization}

The interactions between experimental parameters were important for the experimental results while it had been ignored during the single factor experiment, thus, RSM was applied to optimize the experimental process and order the significance of experimental parameters $[13,29,30]$. In this paper, the experimental parameters affected the reduction process were selected as A (m $(\mathrm{C}) / \mathrm{m}(\mathrm{Cr}))$, B (Reaction Temperature), C (Reaction Time) and $\mathrm{D}$ (Concentration of $\mathrm{H} 2 \mathrm{SO} 4)$. The actual values for them were confirmed through the single factor experimental results and displayed in Table 1.

Table 1 Independent variables and factors levels

\begin{tabular}{|c|c|c|c|c|}
\hline \multirow{2}{*}{ Independent variable } & \multirow{2}{*}{ Unit } & \multicolumn{3}{|c|}{ Level } \\
\hline & & -1 & 0 & 1 \\
\hline $\mathrm{A}: \mathrm{m}(\mathrm{C}) / \mathrm{m}(\mathrm{Cr})$ & - & 0.5 & 1.75 & 3.0 \\
\hline B: Reaction Temperature & ${ }^{\circ} \mathrm{C}$ & 30 & 60 & 90 \\
\hline C: Reaction Time & $\min$ & 10 & 35 & 60 \\
\hline D: Concentration of $\mathrm{H}_{2} \mathrm{SO}_{4}$ & $\mathrm{~g} / \mathrm{L}$ & 0 & 10 & 20 \\
\hline
\end{tabular}

\section{Results and Discussions}

The dosage of biochar had a significant effect on the reduction of $\mathrm{Cr}$ (VI) as it was the main reaction reagent. A series of experiments were conducted to investigate the effect of the 
dosage of biochar $(\mathrm{m}(\mathrm{C}) / \mathrm{m}(\mathrm{Cr}))$ on the reduction efficiency of $\mathrm{Cr}(\mathrm{VI})$. The $\mathrm{m}(\mathrm{C}) / \mathrm{m}(\mathrm{Cr})$ was set as $\mathrm{m}(\mathrm{C}) / \mathrm{m}(\mathrm{Cr})=0.5,1.0,1.5,2.0,2.5$ and 3.0, respectively. The other reaction conditions were kept as constant: reaction temperature of $90{ }^{\circ} \mathrm{C}$, reaction time of $60 \mathrm{~min}$ and concentration of $\mathrm{H} 2 \mathrm{SO} 4$ at $10 \mathrm{~g} / \mathrm{L}$. The results shown in Figure 1a indicated that the reduction efficiency of $\mathrm{Cr}(\mathrm{VI})$ was increased with the increasing of $\mathrm{m}(\mathrm{C}) / \mathrm{m}(\mathrm{Cr})$. The reduction efficiency of $\mathrm{Cr}$ (VI) was increased from $40.32 \%$ to $97.74 \%$ as dosage of biochar increased from $\mathrm{m}(\mathrm{C}) / \mathrm{m}(\mathrm{Cr})=0.5$ to $\mathrm{m}(\mathrm{C}) / \mathrm{m}(\mathrm{Cr})=3.0$. Thus, the $\mathrm{m}(\mathrm{C}) / \mathrm{m}(\mathrm{Cr})=3.0$ was selected for further experiments.

Reaction temperature played an important role in a standard chemical reaction. A series of experiments were conducted to investigate the effect of reaction temperature on the reduction efficiency of $\mathrm{Cr}(\mathrm{VI})$ and the reaction temperature was set as 30,45,60,75, and $90{ }^{\circ} \mathrm{C}$, respectively. The other reaction conditions were kept as constant: $\mathrm{m}(\mathrm{C}) / \mathrm{m}(\mathrm{Cr})=3.0$, reaction time of $60 \mathrm{~min}$ and concentration of $\mathrm{H} 2 \mathrm{SO} 4$ at $10 \mathrm{~g} / \mathrm{L}$. It could be seen from Figure $1 \mathrm{~b}$ that the reduction efficiency was increased with the increasing of reaction temperature, and the increasing trend of reduction efficiency was similar with dosage of biochar, which indicated that both dosage of biochar and reaction temperature had significant effect on the reduction process. Higher temperature could intensify the activity of biochar molecule and $\mathrm{Cr}(\mathrm{VI})$ ion, promoted the extent of the reduction reaction and enforced the reduction of $\mathrm{Cr}$ (VI) $[12,13,31]$. Therefore, $90^{\circ} \mathrm{C}$ was selected as the optimal reaction temperature for further experiments.

Recent study indicated that $\mathrm{Cr}$ (VI) was easy being reduced to $\mathrm{Cr}$ (III) in the strong acidic medium [12, 13, 21]. A series of experiments were conducted at the concentration of $\mathrm{H} 2 \mathrm{SO} 4$ ranged from $0 \mathrm{~g} / \mathrm{L}$ to $20 \mathrm{~g} / \mathrm{L}$ at various dosage of biochar. Figure $1 \mathrm{c}$ displayed that the increase of concentration of $\mathrm{H} 2 \mathrm{SO} 4$ could facilitate the reduction process of $\mathrm{Cr}(\mathrm{VI})$. In theoretical, the formation of $\mathrm{HCrO} 4$ - was the main species of $\mathrm{Cr}(\mathrm{VI})$ at $0.8<\mathrm{pH}<6.8$, and $\mathrm{CrO} 42-$ was the main species at $\mathrm{pH}>6.8$ (Figure 2a measured by software Visual MINTEQ [32]). Other way, $\mathrm{HCrO} 4-$ was easier reduced into $\mathrm{Cr}$ (III) than $\mathrm{CrO} 42-$ as $\mathrm{HCrO} 4-$ the oxidation potential was higher according to the results showed in Figure $2 \mathrm{~b}(\mathrm{E} 0(\mathrm{HCrO} 4-$ $/ \mathrm{Cr} 3+)=1.35 \mathrm{~V}, \mathrm{E} 0(\mathrm{CrO} 42-/ \mathrm{Cr} 3+)=0.56 \mathrm{~V})$. When the dosage of biochar was much high, the reduction efficiency had no obvious increase (when $\mathrm{m}(\mathrm{C}) / \mathrm{m}(\mathrm{Cr})$ was up 2.5 , the reduction efficiency of $\mathrm{Cr}(\mathrm{VI})$ was nearly $100 \%$ at $10 \mathrm{~g} / \mathrm{L})$. Thus, concentration of H2SO4 at $10 \mathrm{~g} / \mathrm{L}$ was enough for further experiments.

Figure $1 \mathrm{~d}$ described the effect of reaction time on the reduction process at various reaction temperatures as other reaction conditions kept as $m(C) / m(C r)=3.0$ and concentration of $\mathrm{H} 2 \mathrm{SO} 4$ at $10 \mathrm{~g} / \mathrm{L}$. The results showed that the extend the reaction time could improve the reduction efficiency of $\mathrm{Cr}(\mathrm{VI})$ at all reaction temperature. And higher reaction temperature was beneficial for the reduction process, which was consistent with the analysis above. 


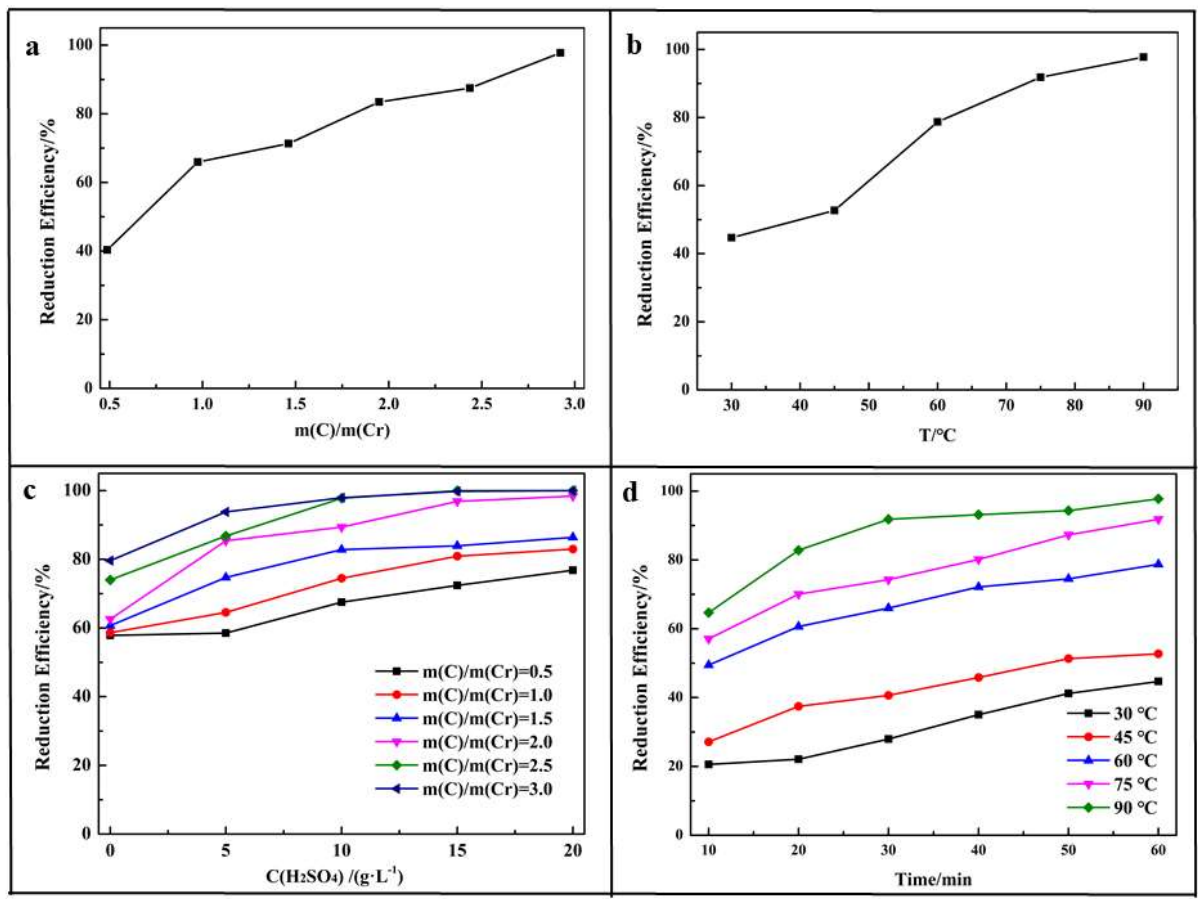

Figure 1 Effect of the single parameters on the reduction process. (a- dosage of biochar $(\mathrm{m}(\mathrm{C}) / \mathrm{m}(\mathrm{Cr}))$; b-Reaction temperature; c-Concentration of $\mathrm{H} 2 \mathrm{SO} 4$; d- Reaction time)
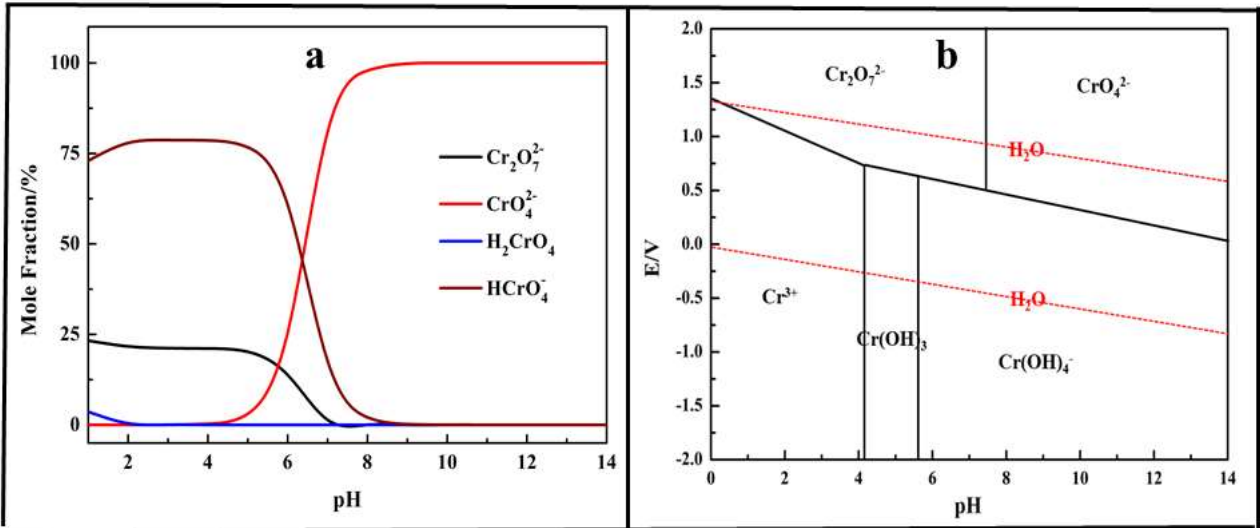

Figure $2 \mathrm{a}-\mathrm{Cr}(\mathrm{VI})$ species in the solution at various $\mathrm{pH}$; $\mathrm{b}$-the E-pH diagram of chromium

\subsection{Response Surface Methodology}

\subsubsection{Model fitting}

The squares root was used to express the simulated results and it was presented in Equation (2):

sqrt $(\eta)=8.38+0.55^{*} \mathrm{~A}+0.38^{*} \mathrm{~B}+0.27^{*} \mathrm{C}+0.52^{*} \mathrm{D}-0.17^{*} \mathrm{AB}+0.22^{*} \mathrm{AC}+0.25^{*} \mathrm{AD}-0.025^{*} \mathrm{BC}+$ 
The influence of each parameter on the reduction efficiency of $\mathrm{Cr}$ (VI) could be seen from the coefficients before them in the Equation (2). The coefficients of them were 0.55, 0.38, 0.27 and 0.52 , respectively, which confirmed that all the parameters had a positive effect on the reduction efficiency. The results displayed in Figure 3 indicated that the influence of each parameter on the reduction efficiency followed the order: A $>$ D $>$ B $>$ C, which was consistent with the results described in Equation (2). Above all, the dosage of biochar and concentration of $\mathrm{H} 2 \mathrm{SO} 4$ had the greatest influence on the reduction process.

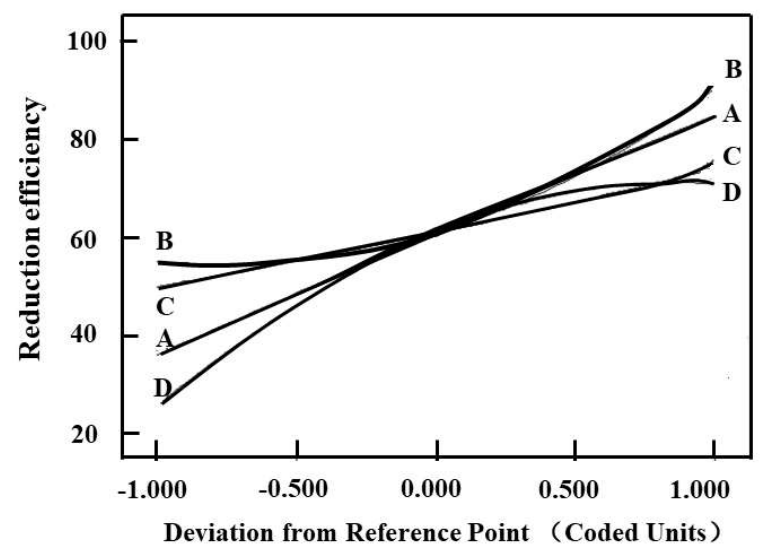

Figure 3 Perturbation plot for the reduction efficiency of $\mathrm{Cr}(\mathrm{VI})$ in the design space. (A- $(\mathrm{m}(\mathrm{C}) / \mathrm{m}(\mathrm{Cr}))$; B- (Reaction Temperature); C- (Reaction Time) and D- (Concentration of H2SO4)).

The analysis of variance of the reduction efficiency of Cr (VI) was shown in Table 2. The results showed that the $\mathrm{p}$-value of the model was $<0.0001$, which indicated that the selected model was significant and suitable for simulating the reduction process of $\mathrm{Cr}$ (VI) $[30,33]$

Table 2 Analysis of variance for the response

\begin{tabular}{|c|c|c|c|c|c|}
\hline \multirow{3}{*}{ Source } & \multirow{3}{*}{ Sum of Squares } & \multirow{3}{*}{ Z } & Mean & \multirow[t]{2}{*}{$\mathrm{F}$} & \multirow[t]{2}{*}{$\mathrm{p}$-value } \\
\hline & & & & & \\
\hline & & & square & value & Prob $>F$ \\
\hline Model & 11.76 & 14 & 0.84 & 14.47 & $<0.0001$ \\
\hline A & 3.60 & 1 & 3.60 & 62.00 & $<0.0001$ \\
\hline B & 1.76 & 1 & 1.76 & 30.29 & $<0.0001$ \\
\hline $\mathrm{C}$ & 0.87 & 1 & 0.87 & 15.05 & 0.0017 \\
\hline $\mathrm{D}$ & 3.31 & 1 & 3.31 & 56.94 & $<0.0001$ \\
\hline $\mathrm{AB}$ & 0.12 & 1 & 0.12 & 2.10 & 0.1690 \\
\hline $\mathrm{AC}$ & 0.19 & 1 & 0.19 & 3.36 & 0.0882 \\
\hline $\mathrm{AD}$ & 0.24 & 1 & 0.24 & 4.22 & 0.0591 \\
\hline $\mathrm{BC}$ & $2.54 \mathrm{E}-003$ & 1 & $2.54 \mathrm{E}-003$ & 0.044 & 0.8372 \\
\hline $\mathrm{BD}$ & 0.26 & 1 & 0.26 & 4.39 & 0.0547 \\
\hline
\end{tabular}




\begin{tabular}{cccccc}
\hline $\mathrm{CD}$ & 0.16 & 1 & 0.16 & 2.67 & 0.1243 \\
$\mathrm{~A}^{2}$ & $5.787 \mathrm{E}-003$ & 1 & $5.787 \mathrm{E}-003$ & 0.100 & 0.7569 \\
$\mathrm{~B}^{2}$ & 0.41 & 1 & 0.41 & 0.044 & 0.8375 \\
$\mathrm{C}^{2}$ & $2.533 \mathrm{E}-003$ & 1 & $2.533 \mathrm{E}-003$ & 0.32 & 0.0063 \\
$\mathrm{D}^{2}$ & 0.60 & 1 & 0.60 & - & - \\
Residual & 0.81 & 14 & 0.058 & - & - \\
Lack-of-fit & 0.81 & 10 & 0.081 & 0.000 & - \\
Pure error & 0.000 & 4 & & & - \\
\hline
\end{tabular}

\subsubsection{Response surface analysis}

To evaluate the fitting effect of the model on the experimental results, some other important diagnostic plots including Internally Studentized Residuals against Run Number, Predicted against Actual, Internally Studentized Residuals against Predicted and Normal Probability against Internally Studentized Residuals, respectively, were shown in Figure 4. All points showed in the Normal Probability against Internally Studentized Residuals plot shown in Figure 4a was concentrated in a straight line illustrated that the error was normally distributed. In a plot of Internally Studentized Residuals against Run Number and Internally Studentized Residuals against Predicted, the residuals were randomly distributed between +3.00 and -3.00 , indicating that the Box-Behnken model was successfully established the relationship between the independent variable and the reduction efficiency. A plot of Predicted against Actual was shown in Figure $4 \mathrm{~b}$, the points were approximately distributed on a straight line with a slope of 1 , which indicated that this model could accurately predict the actual value. 


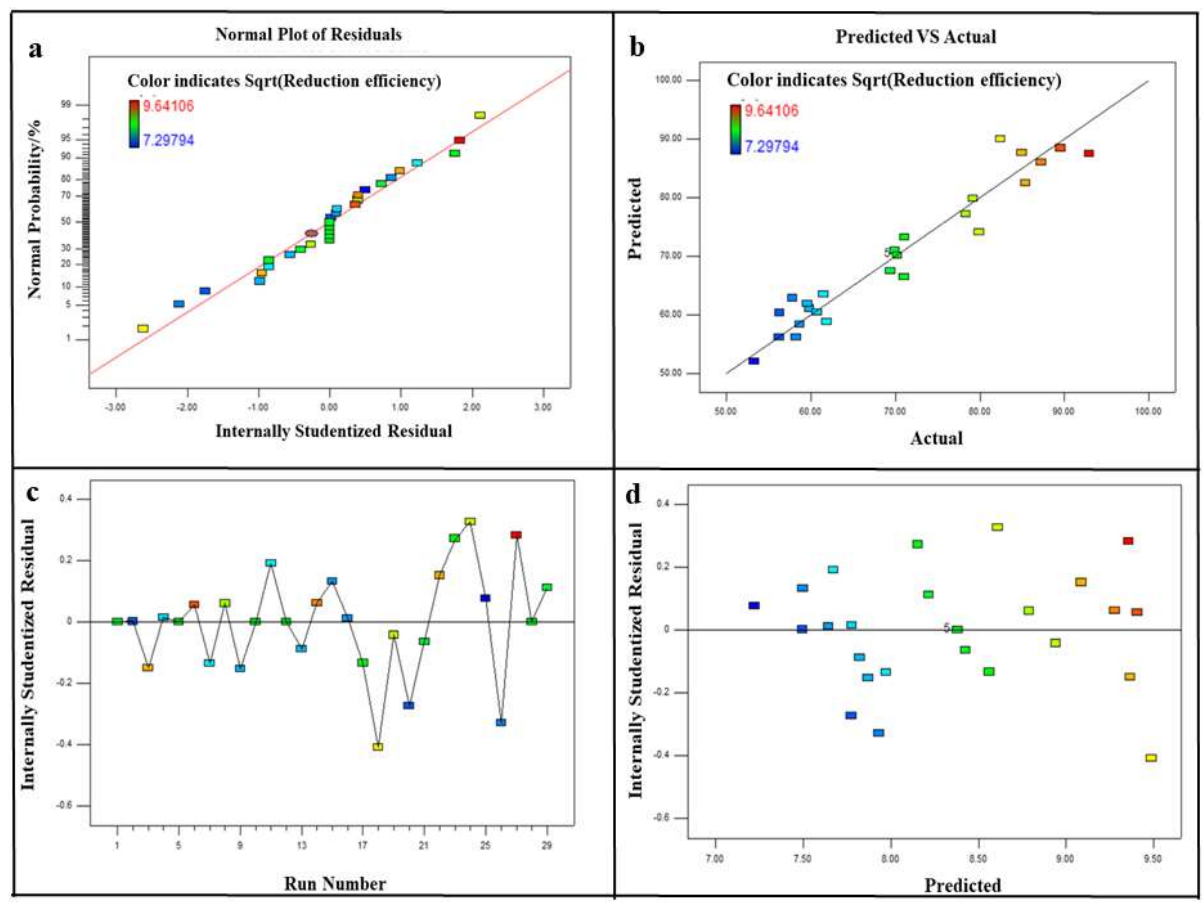

Figure 4 Diagnostic plots of the quadratic model. (a- Normal Probability against Internally Studentized Residuals; b- Predicted against Actual; c-Internally Studentized Residuals against Run Number; d- Internally Studentized Residuals against Predicted)

The contour plots were applied to analysis the interaction between experimental parameters. Figure 5 showed that the reduction efficiency of $\mathrm{Cr}(\mathrm{VI})$ was increased with the increase of all experimental parameters and the results were consistent with the analysis above. 

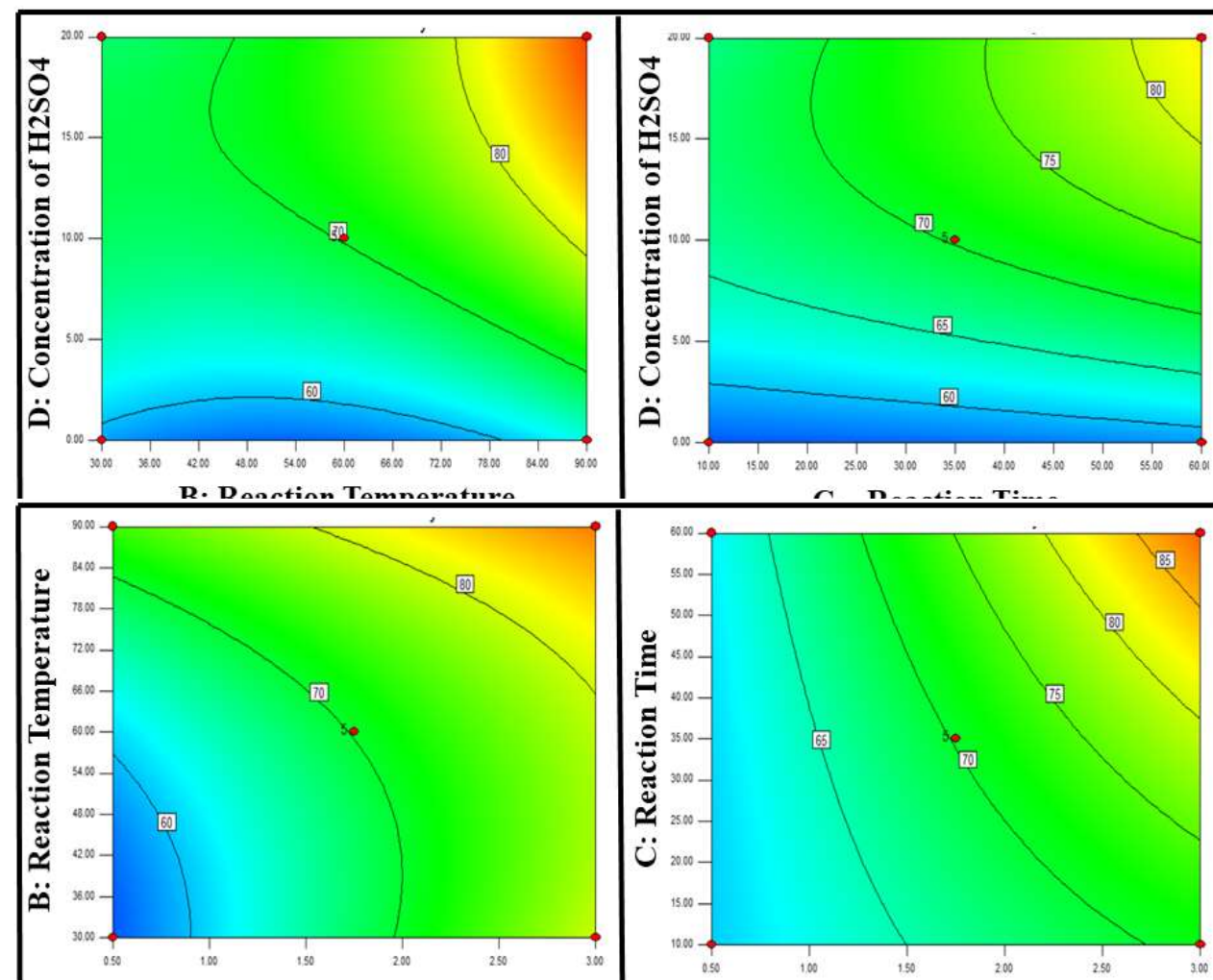

A: $\mathbf{m}(\mathrm{C}): \mathbf{m}(\mathrm{Cr})$
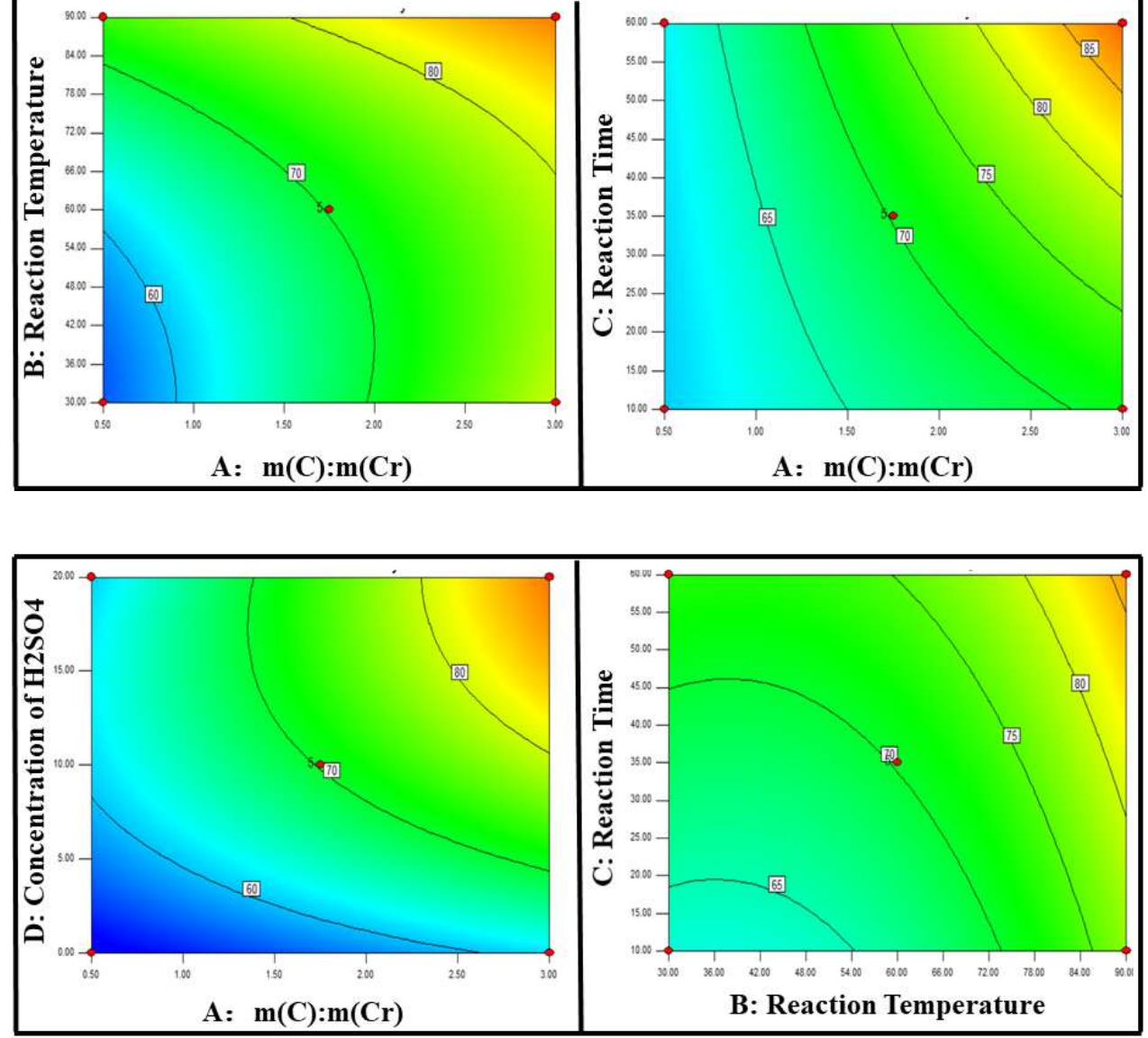

Figure 5 Response surface plots for factors

3.3 Reduction Kinetics Analysis

In this paper, pseudo-first-order model as described as Equation (3) was applied to simulated the reduction behavior of $\mathrm{Cr}$ (VI) [33-36].

$v=\mathrm{dC} / \mathrm{dt}=-\mathrm{KC}$

Integrate.

$-\operatorname{LnC}=\mathrm{Kt}-\operatorname{Ln} \mathrm{C}_{0}$ 
Where, $\mathrm{v}$, is the reduction rate of $\mathrm{Cr}(\mathrm{VI})$; $\mathrm{C}$, is the concentration of $\mathrm{Cr}(\mathrm{VI})$; $\mathrm{C} 0$, is the initial concentration of $\mathrm{Cr}(\mathrm{VI}) ; \mathrm{K}$, is the reduction reaction constant.

Figure 6a displayed the fitting results of experimental results fitted with Equation (4), which indicated that the reduction process of $\mathrm{Cr}(\mathrm{VI})$ was fitted well with the pseudo-firstorder model. The reduction reaction apparent activation energy was obtained by simulating the experimental results with the Arrhenius Equation (Equation (5)). The apparent activation energy was calculated as $40.24 \mathrm{~kJ} / \mathrm{mol}$ according to the results showed in Figure $6 \mathrm{~b}$, which was much larger than the apparent energy calculated for reduction with oxalic acid $(22.49 \mathrm{~kJ} / \mathrm{mol})$ [21] and electrochemical reduction $(4.74 \mathrm{~kJ} / \mathrm{mol})$ [12]. It meant that the reduction process with biochar was harder than oxalic acid and electrochemical reduction.

$\ln \mathrm{K}=\mathrm{Ln} \mathrm{A}-\mathrm{Ea} / \mathrm{RT}$

Where, Ea, is the apparent activation energy; A, is the pre-exponential factor; $\mathrm{R}$, is the molar gas constant, $8.314 \mathrm{~J} /(\mathrm{mol} \mathrm{K}) ; \mathrm{K}$, is the reduction reaction constant at different reaction temperatures.
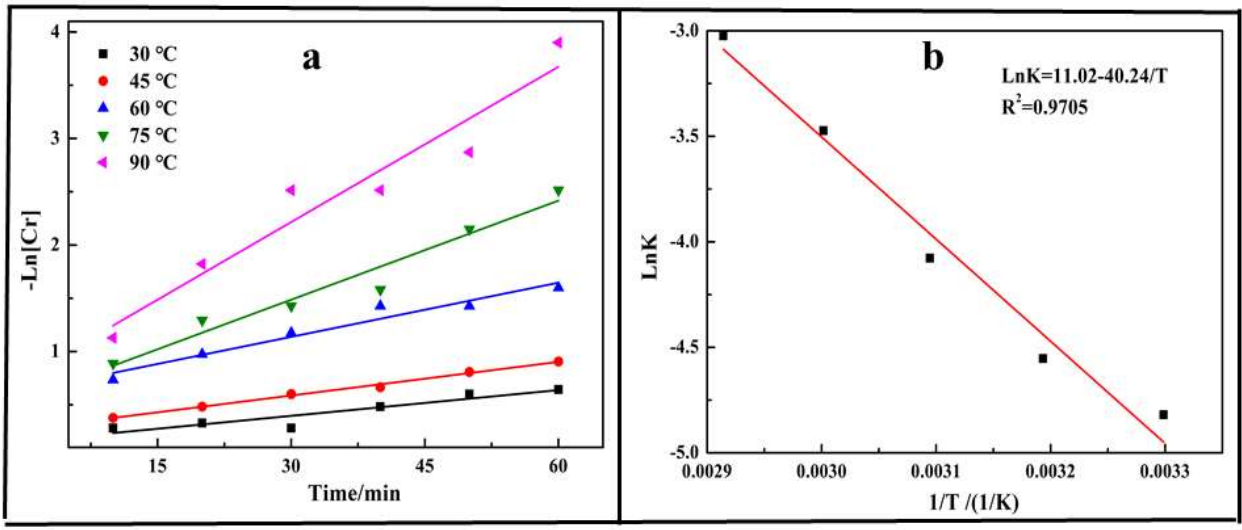

Figure 6 Kinetics plots: a) Plot of reduction kinetics at various reaction temperatures; b) Natural logarithm of reduction reaction constant vs reciprocal reaction temperature

\subsection{Removal of Chromium (III)}

After the reduction process, the $\mathrm{Cr}$ (VI) was reduced to $\mathrm{Cr}$ (III) and it was removed by precipitation with sodium hydroxide [37] or adsorption with melamine [19, 20].

\section{Conclusions}

A highly efficient reduction process of $\mathrm{Cr}(\mathrm{VI})$ with biochar was investigated and the following conclusions could be obtained:

(1) The Cr (VI) was easily being reduced by biochar at high reaction temperature with high dosage of biochar in strong acidic medium. Nearly $100 \% \mathrm{Cr}$ (VI) was reduced at selected reaction conditions: the dosage of biochar at $\mathrm{m}(\mathrm{C}) / \mathrm{m}(\mathrm{Cr})=3.0$, reaction temperature of $90{ }^{\circ} \mathrm{C}$, reaction time at $60 \mathrm{~min}$ and concentration of $\mathrm{H} 2 \mathrm{SO} 4$ of $20 \mathrm{~g} / \mathrm{L}$, respectively.

(2) The reduction kinetics analysis indicated that the reduction behavior of $\mathrm{Cr}$ (VI) fitted well with the pseudo-first-order model and the apparent activation energy was calculated as $40.24 \mathrm{~kJ} / \mathrm{mol}$. 
(3) Response surface methodology confirmed that all the experimental parameters had positive effect on the reduction of $\mathrm{Cr}(\mathrm{VI})$. The influence of each parameter on the reduction process followed the order: A (dosage of biochar $(\mathrm{m}(\mathrm{C}) / \mathrm{m}(\mathrm{Cr}))>\mathrm{D}($ Concentration of H2SO4) > B (Reaction Temperature) > C (Reaction Time). Especially, the dosage of biochar and concentration of $\mathrm{H} 2 \mathrm{SO} 4$ had the greatest influence on the reduction process.

\begin{abstract}
Author Contributions: Conceptualization, Hao Peng.; methodology, Hao Peng.; software, Hao Peng; validation, Hao Peng; formal analysis, Hao Peng; investigation, Jing Guo; resources, Hao Peng; data curation, Jing Guo; writing - original draft preparation, Hao Peng; writing - review and editing, Hao Peng; visualization, Hao Peng; supervision, Hao Peng; project administration, Hao Peng; funding acquisition, Hao Peng. All authors have read and agreed to the published version of the manuscript."

Funding: This work was supported by the Science and Technology Research Program of Chongqing Municipal Education Commission (No. KJQN201901403 and No. CXQT20026) and Chongqing Science and Technology Commission (No. cstc2018jcyjAX0018).
\end{abstract}

Conflicts of Interest: The authors declare no conflict of interest

\title{
References
}

1. J. Song, H. Kong, J. Jang, Adsorption of heavy metal ions from aqueous solution by polyrhodanine-encapsulated magnetic nanoparticles, J Colloid Interf Sci, 359 (2011) 505-511.

2. G.Z. Kyzas, K.A. Matis, Nanoadsorbents for pollutants removal: A review, Journal of Molecular Liquids, 203 (2015) $159-168$.

3. V. Nogueira, I. Lopes, T. Rocha-Santos, F. Gonçalves, R. Pereira, Toxicity of solid residues resulting from wastewater treatment with nanomaterials, Aquat Toxicol, 165 (2015) 172-178.

4. N. Adhoum, L. Monser, N. Bellakhal, J.-E. Belgaied, Treatment of electroplating wastewater containing Cu2+, Zn2+ and Cr(VI) by electrocoagulation, Journal of hazardous materials, 112 (2004) 207-213.

5. M. Hunsom, K. Pruksathorn, S. Damronglerd, H. Vergnes, P. Duverneuil, Electrochemical treatment of heavy metals (Cu2+, Cr6+, Ni2+) from industrial effluent and modeling of copper reduction, Water research, 39 (2005) 610-616.

6. H. Peng, J. Guo, Removal of chromium from wastewater by membrane filtration, chemical precipitation, ion exchange, adsorption electrocoagulation, electrochemical reduction, electrodialysis, electrodeionization, photocatalysis and nanotechnology: a review, Environmental Chemistry Letters, (2020).

7. A. Azimi, A. Azari, M. Rezakazemi, M. Ansarpour, Removal of Heavy Metals from Industrial Wastewaters: A Review, ChemBioEng Reviews, 4 (2017) 37-59.

8. H. Xin, Q. Xinhong, C. Jinyi, Preparation of Fe(II)-Al layered double hydroxides: Application to the adsorption/reduction of chromium, Colloids and Surfaces A: Physicochemical and Engineering Aspects, 516 (2017) 362-374.

9. R. Fu, X. Zhang, Z. Xu, X. Guo, D. Bi, W. Zhang, Fast and highly efficient removal of chromium (VI) using humus-supported nanoscale zero-valent iron: Influencing factors, kinetics and mechanism, Sep Purif Technol, 174 (2017) 362-371.

10. H. Peng, J. Guo, B. Li, Z. Liu, C. Tao, High-efficient recovery of chromium (VI) with lead sulfate, Journal of the Taiwan Institute of Chemical Engineers, 85 (2018) 149-154.

11. Y. Zhao, Removal of Chromium Using Electrochemical Approaches: A Review, Int J Electrochem Sc, 13 (2018) $1250-1259$.

12. H. Peng, Y. Leng, J. Guo, Electrochemical Removal of Chromium (VI) from Wastewater, Applied Sciences, 9 (2019) 1156.

13. H. Peng, Y. Leng, Q. Cheng, Q. Shang, J. Shu, J. Guo, Efficient Removal of Hexavalent Chromium from Wastewater with ElectroReduction, Processes, 7 (2019) 41.

14. Z. Zhao, a. He, J. Lin, M. Feng, V. Murugadoss, T. Ding, H. Liu, Q. Shao, X. Mai, N. Wang, H. Gu, S. Angaiah, Z. Guo, Progress on the Photocatalytic Reduction Removal of Chromium Contamination, Chem Rec, 19 (2019) 873-882.

15. X. Zheng, F. Kang, X. Liu, H. Peng, Z. JinYang, Carbon-coated Mg-Al layered double oxide nanosheets with enhanced removal of hexavalent chromium, J Ind Eng Chem, 80 (2019) 53-64.

16. X.Q. Liu, G. Zhang, H.Q. Xing, P. Huang, X.L. Zhang, Preparation of amphiphilic composite and removal of oil and hexavalent chromium from wastewater, Environmental Chemistry Letters, 9 (2011) 127-132.

17. C. He, L. Gu, Z. Xu, H. He, G. Fu, F. Han, B. Huang, X. Pan, Cleaning chromium pollution in aquatic environments by bioremediation, photocatalytic remediation, electrochemical remediation and coupled remediation systems, Environmental Chemistry Letters, 18 (2020) 561-576.

18. G.P. Gallios, M. Vaclavikova, Removal of chromium (VI) from water streams: a thermodynamic study, Environmental Chemistry Letters, 6 (2008) 235-240.

19. H. Peng, Q. Shang, R. Chen, L. Zhang, Y. Chen, J. Guo, Step-Adsorption of Vanadium (V) and Chromium (VI) in the Leaching Solution with Melamine, Sci Rep-Uk, 10 (2020) 6326. 
20. J. Guo, R. Chen, L. Zhang, Q. Shang, Y. Chen, H. Peng, Adsorption of Chromium (III) on Melamine: Kinetic, Isotherm, Thermodynamics and Mechanism Analysis, IOP Conference Series: Earth and Environmental Science, 512 (2020) 012076.

21. H. Peng, J. Guo, Reduction behavior of chromium(VI) with oxalic acid in aqueous solution, Sci Rep-Uk, 10 (2020) 17732.

22. A. Ashiq, B. Sarkar, N. Adassooriya, J. Walpita, A.U. Rajapaksha, Y.S. Ok, M. Vithanage, Sorption process of municipal solid waste biochar-montmorillonite composite for ciprofloxacin removal in aqueous media, Chemosphere, 236 (2019) 124384.

23. W.-H. Huang, D.-J. Lee, C. Huang, Modification on biochars for applications: A research update, Bioresource Technol, 319 (2021) 124100.

24. X. Zheng, Y. Zhou, X. Liu, X. Fu, H. Peng, S. Lv, Enhanced adsorption capacity of MgO/N-doped active carbon derived from sugarcane bagasse, Bioresource Technol, 297 (2020) 122413.

25. M.B. Ahmed, J.L. Zhou, H.H. Ngo, W. Guo, M.A.H. Johir, D. Belhaj, Competitive sorption affinity of sulfonamides and chloramphenicol antibiotics toward functionalized biochar for water and wastewater treatment, Bioresource Technol, 238 (2017) 306-312.

26. R.R. Karri, J.N. Sahu, B.C. Meikap, Improving efficacy of Cr (VI) adsorption process on sustainable adsorbent derived from waste biomass (sugarcane bagasse) with help of ant colony optimization, Industrial Crops and Products, 143 (2020) 111927.

27. M. Zubair, I. Ihsanullah, H. Abdul Aziz, M. Azmier Ahmad, M.A. Al-Harthi, Sustainable wastewater treatment by biochar/layered double hydroxide composites: Progress, challenges, and outlook, Bioresource Technol, 319 (2021) 124128.

28. H. Peng, L. Yang, L. Wang, J. Guo, B. Li, Recovery of vanadium with urea in acidic medium, Environmental Chemistry Letters, 17 (2019) 1867-1871.

29. H. Peng, Q. Shang, R. Chen, Y. Leng, J. Guo, Z. Liu, C. Tao, Oxidative Leaching Kinetics of Vanadium from the VanadiumChromium-Reducing Residue with K2Cr2O7, ACS Omega, 5 (2020) 8777-8783.

30. H. Peng, F. Wang, G. Li, J. Guo, B. Li, Highly Efficient Recovery of Vanadium and Chromium: Optimized by Response Surface Methodology, ACS Omega, 4 (2019) 904-910.

31. H. Peng, L. Yang, Y. Chen, J. Guo, B. Li, Recovery and Separation of Vanadium and Chromium by Two-Step Alkaline Leaching Enhanced with Electric Field and H2O2, ACS Omega, (2020) 5340-5345.

32. J.P. Gustafsson, Visual MINTEQ ver. 3.0, in, 2014.

33. H. Peng, Q. Shang, R. Cheng, L. Zhang, Y. Chen, J. Guo, Highly efficient oxidative-alkaline-leaching process of vanadiumchromium reducing residue and parameters optimization by response surface methodology, Environ Technol, (2020) 1-10.

34. V.A. Okello, S. Mwilu, N. Noah, A. Zhou, J. Chong, M.T. Knipfing, D. Doetschman, O.A. Sadik, Reduction of hexavalent chromium using naturally-derived flavonoids, Environmental Science and Technology, 46 (2014) 10743-10751.

35. X. Zhang, W. Fu, Y. Yin, Z. Chen, R. Qiu, M.-O. Simonnot, X. Wang, Adsorption-reduction removal of Cr(VI) by tobacco petiole pyrolytic biochar: Batch experiment, kinetic and mechanism studies, Bioresour Technol, 268 (2018) 149-157.

36. G. Chen, J. Han, Y. Mu, H. Yu, L. Qin, Two-stage chromium isotope fractionation during microbial Cr(VI) reduction, Water Research, 148 (2019) 10-18.

37. B. Chen, S. Huang, B. Liu, Q. Ge, M. Wang, X. Wang, Separation and recovery of vanadium and chromium from acidic leach solution of V-Cr-bearing reducing slag, Journal of Environmental Chemical Engineering, 5 (2017) 4702-4706. 